\title{
Winter-hardy vs. freeze-killed cover crop mixtures before maize in an organic farming system with reduced soil cultivation
}

\author{
Gabriele Gollner (D) • Julia Fohrafellner • \\ Juergen Kurt Friedel (D)
}

Received: 1 April 2020 / Accepted: 15 April 2020 / Published online: 27 April 2020

(C) The Author(s) 2020

\begin{abstract}
The advantages and disadvantages of a winter-hardy vs. a freeze-killed cover crop mixture combined with reduced soil cultivation to a following maize crop were studied on an organic farm in Lower Austria in two consecutive experiments. Effects on soil inorganic nitrogen contents, weed density and the yield of a following maize crop were assessed. The winter-hardy compared with freeze-killed cover crop mixture, both consisting of legumes and non-legumes, reduced soil inorganic nitrogen contents over winter, leading to a reduced nitrate leaching risk, whereas the yield of a following grain maize crop was not significantly affected. Weed density was high in both cover crop treatments, presumably due to the continued reduced, noninverting soil cultivation on the farm, and higher in the winter-hardy cover crop treatment at one of the assessment dates. Combined with an adapted soil cultivation, both the winter-hardy and the freeze-killed cover crop mixture were suitable before grain maize in this organic farming system with non-inverting soil cultivation under moderately dry site conditions, but the winter-hardy
\end{abstract}

G. Gollner · J. K. Friedel

Division of Organic Farming, Department of Sustainable

Agricultural Systems, University of Natural Resources and Life

Sciences, 1180 Vienna, Austria

G. Gollner $(\bowtie) \cdot$ J. Fohrafellner · J. K. Friedel

University of Natural Resources and Life Sciences, 1180 Vienna, Austria

e-mail: gabriele.gollner@boku.ac.at cover crop mixture seems advantageous because it reduces the nitrate leaching risk.

Keywords Catch crops $\cdot$ Nitrate leaching $\cdot$ Weed pressure $\cdot$ Pre-crop effect $\cdot$ Grain maize yield

\section{Introduction}

Cover crop (CC) mixtures have multiple advantages compared with bare soil. Mixtures of legumes and non-legumes reduce erosion by covering the soil, fixing nitrogen from the air, reducing nitrate leaching, adding organic matter to the soil, increasing soil biological activity, and improving soil structure and porosity. It can mobilize nutrients like potassium or phosphorus, can reduce weed density by competing with weeds, and can increase the yield of following main crops by providing nutrients from their biomass (e.g. Rinnofner et al. 2008; Bodner et al. 2010; Wanic et al. 2018). Freeze-killed cover crops have a possible risk to support nitrate leaching, when the nitrogen saved in the biomass is mineralised in autumn and during winter. Winterhardy cover crops reduce the risk for nitrate leaching, because the growing plants take up nutrients permanently. On the other side, winter-hardy cover crops need an intensive soil cultivation for termination in organic farming systems, which could increase erosion risk; otherwise, they could compete with the following crop. Freeze-killed cover crops require no special soil tillage, reduce soil tillage, or no-tillage is possible. Therefore, the protection against erosion is ensured. However, the 
soil warms up later; the germination conditions for a following maize crop are inferior, and they can prevent nitrate leaching only until freezing sets in. Subsequently, their residues are mineralized and a major portion of the fixed nitrogen is released before maize sowing.

However, the advantages and disadvantages of winter-hardy vs. freeze-killed cover crop (CC) mixtures have not been studied systematically. The objectives of our study were to test if a winter-hardy CC mixture terminated with a rotary cultivator compared with freeze-killed CC mixture worked into the soil with a chisel (i) reduces soil inorganic nitrogen contents over winter, (ii) decreases or increases weed density, and (iii) increases the yield of the following crop, i.e. a following grain maize crop in this study.

\section{Material and methods}

Site and soil

Two field experiments (FE1 and FE2) were carried out in 2016-2019 in Raipoltenbach, on an organic farmer's field. Raipoltenbach is located between Vienna and St. Pölten (48 $\left.12^{\prime} 26.93^{\prime \prime} \mathrm{N} 15^{\circ} 53^{\prime} 17.09^{\prime \prime} \mathrm{E}\right)$ in Lower Austria at an altitude of $251 \mathrm{~m}$ above sea level. The mean annual air temperature is $9.9^{\circ} \mathrm{C}$ and the average precipitation is $629 \mathrm{~mm}_{\text {year }}{ }^{-1}$. The soil was an orthic Luvisol. The topsoil had a silty clay (FE1) and silty loam (FE2) texture, a $\mathrm{pH}_{\mathrm{CaCl} 2}$ value of 7.4 (FE1) and 6.7 (FE2), a sufficient level of available phosphorus (P) and a low (FE1) to sufficient (FE2) level of available potassium (K). No livestock has been on the farm since 1998. Soil cultivation on the farm has usually been noninversion tillage with either a rotary cultivator or a chisel. Occasionally, when weed density was high, the soil was ploughed.

Experimental set-up and management practice

The two field experiments (FE1 and FE2) with two CC/ soil cultivation treatments in four replicates (randomized complete block design) were conducted in two consecutive years. The winter-hardy CC (WCC) mixture was "Landsberger Gemenge" (seeding rate in $\mathrm{kg} \mathrm{ha}^{-1}$ in brackets) consisting of winter vetch (102.5), crimson clover (11.3) and Italian ryegrass (11.3). The freezekilled CC (FCC) mixture consisted of fodder pea (142.0), common vetch (58.0), chickling vetch (50.0), buckwheat (12.0), phacelia (8.5) and fodder radish (8.5). CCs were sown on 9 August 2016 / 22 August 2017 in FE1 and FE2, respectively. The FCC was worked into the soil with a chisel. The WCC catch crop mixture was terminated with a rotary cultivator on 4 April 2017/19 April 2018. After chiselling the soil (only in FE1), maize, cv "Connexxion RZ 340", was sown on 4 May 2017/7 May 2018. In both treatments, soil was harrowed once in May and hoed twice in June. Only in the WCC treatment, an underseed of Egyptian clover, squarrose clover, linseed, phacelia, Persian clover, serradella, white clover and ryegrass was established on 24 June 2017/18 July 2018.

The weed pressure in the experimental plots was evaluated several times in FE2 in 2018 by estimating a value for area infested with weeds per plot (\%). On the last assessment date, thistle plants per square meter were assessed. After maize harvest in October, the subsequent crop soybean was sown in May 2018/2019 (cv. Bettina; seeding density $130 \mathrm{~kg} \mathrm{ha}^{-1}$ ) and harvested in September (data not shown).

Sampling and analytical methods

In November 2016/April 2017 (FE1) and November 2017/April 2018 (FE2), the biomass of the cover crop mixtures (FCC/WCC, respectively) was determined by harvesting six areas per plot $\left(1 \mathrm{~m}^{2}\right)$ and collecting the plants by hand. The maize harvest was carried out when the maize crop reached maturity in October 2017/2018. All plants of six areas per plot, 1.33-m length within one maize row each, were cut at the bottom and collected by hand. Number of maize plants, corncobs per plant, weight of cobs and weight of plant without cobs were assessed. The dry matter (DM) of maize corn and crop residues, as well as of cover crop biomass, were determined drying an aliquot at $105^{\circ} \mathrm{C}$ to constant weight. Aliquots of the maize corn and residues and of cover crops were dried at $60{ }^{\circ} \mathrm{C}$ for $48 \mathrm{~h}$, ground up to a fine powder, and analysed for plant $\mathrm{N}$ content with an LECO CN-2000 analyzer (Vario Macro Cube, Elementar Analysensysteme $\mathrm{GmbH})$.

During the vegetation period, several visual assessments of maize were conducted. Data about maize height, development stage of maize and plants per square meter, as well as weed pressure, were collected.

Soil samples for determining inorganic $\mathrm{N}$ in three layers $(0-30,30-50$ and $50-90 \mathrm{~cm})$ were taken 4 times from December 2016 to September 2017 in FE1 and 
from April to July 2018 in FE2. Soil inorganic N ( $\left.\mathrm{N}_{\text {in }}\right)$ was extracted from the soil using a $0.0125 \mathrm{M}$ calcium chloride $\left(\mathrm{CaCl}_{2}\right)$ solution at a 1:4 ratio. Extract $\mathrm{NO}_{3}{ }^{-}-\mathrm{N}$ and $\mathrm{NH}_{4}{ }^{+}$-N were measured calorimetrically according to Schlichting et al. (1995) using an UV-VIS-Photometer (measurement of $\mathrm{NH}_{4}{ }^{+}-\mathrm{N}$ at $660 \mathrm{~nm}$ wavelength with $\mathrm{NaOH}$, sodium salicylate, nitroprusside sodium dehydrate, dichlorisocyanuric acid as reagents; measurement of $\mathrm{NO}_{3}{ }^{-}-\mathrm{N}$ at $540-\mathrm{nm}$ wavelength with vanadium(III)-chloride, N-1-naphthylethylendiamine dihydrochloride, sulfanilic acid, hydrochloric acid $32 \%$ as reagents).

\section{Calculations and statistics}

Data was analyzed using IBM SPSS Statistics 24 . The general linear model univariate with an alpha of 0.05 was performed, providing an analysis of variance (ANOVA) for each dependent variable by the fixed factor "treatment" and the random factor "block". Data was logarithmically transformed to fulfil the prerequisite of homogeneity of variances. Spearman rank-order correlation coefficients and its significance levels were calculated with the bivariate correlations procedure.

\section{Results}

Climatic conditions and soil inorganic $\mathrm{N}$

The mean air temperature was close to the long-term average. The precipitation from August at seeding of cover crops until biomass harvest at November was higher in $2016(+60 \mathrm{~mm})$ and $2017(+40 \mathrm{~mm})$ than the long-term precipitation mean (Table 1). From April to May 2017, as well as in July and September 2017 and from May to August 2018, the monthly precipitation was also higher than the long-term values.

The $\mathrm{N}_{\text {in }}$ values in 0-90 cm soil depth in spring (2017 FE1/2018 FE2) were almost doubled in the freeze-killed $\mathrm{CC}$ treatment compared with the winter-hardy $\mathrm{CC}$ treatment (Fig. 1). In FE1 in March 17, the $\mathrm{N}_{\text {in }}$ values of all soil depths were significantly higher in FCC compared with WCC, and in August 17, values did not differ between the treatments. In April 18 in FE2, only in 50-90-cm depth, the $\mathrm{N}_{\text {in }}$ values of FCC were higher than of WCC. In July 18 , the $\mathrm{N}_{\text {in }}$ values were generally very high, but without differences between the treatments (Fig. 1).
Development, biomass and yield of cover crops and maize

The winter-hardy CC developed slower than the freezekilled CC. In November (2016 FE1/2017 FE2), the dry matter biomass of the winter-hardy $\mathrm{CC}\left(1.8 \mathrm{t} \mathrm{ha}^{-1}\right.$ on av.) was lower compared with that of the freeze-killed CC (3.1 t ha ${ }^{-1}$ on av.; Table 2). In April (2017 FE1/2018 FE2), the biomass dry matter of the winter-hardy CC equalled the November values of the freeze-killed CC (Table 2). The biomass $\mathrm{N}$ content and C-to-N ratio (ca. 13 in FE1/10 in FE2) did not differ between both CC treatments.

An assessment in June (FE1) and May (FE2) showed no differences in the number of maize plants per square meter. The undersown crop mixture in the winter-hardy CC treatment developed well in 2017 (FE1) and poorly in 2018 (FE2) due to little precipitation and high temperatures in spring 2018.

Maize grain dry matter yield was $7.8 \mathrm{tha}^{-1}$ in FE1 and $7.0 \mathrm{t} \mathrm{ha}^{-1}$ in FE2 on average and did not differ between treatments. Also, maize nitrogen yield did not differ (Table 2).

Weed pressure

Main weeds determined during the vegetation period 2018 were creeping thistle, chickweed, red dead-nettle and white goosefoot (Chenopodium album). Weed density was moderate until June, but from July to September weeds covered 30 to $80 \%$ of the area in FE2 in 2018 (Fig. 2). Weed density did not differ between the treatments, with one exception: on 3 July 2018, weed density was higher in the winter-hardy CC treatment than in the freeze-killed CC (Fig. 2). The results of thistles per square meter in October 2018 showed an equally high infestation in both treatments (WCC 28, FCC 31 thistles $/ \mathrm{m}^{2}$ ).

\section{Discussion}

The winter-hardy "Landsberger Gemenge" cover crop mixture reached an above-ground biomass of 2.3 to $3.2 \mathrm{t} \mathrm{DM} \mathrm{ha}^{-1}$ in FE1 and FE2. Although this biomass was equal to (FE1) or slightly less (FE2) than the biomass of freeze-killed CC mixture in autumn, the rooting density (results not shown) was higher and $\mathrm{N}_{\text {in }}$ contents were significantly lower in the winter-hardy $\mathrm{CC}$ 
Table 1 Long term (1991-2010) temperature and rainfall at experimental site and respective values for the growing seasons 2016-2018

\begin{tabular}{|c|c|c|c|c|c|c|c|c|}
\hline & \multicolumn{4}{|c|}{ Temperature $\left({ }^{\circ} \mathrm{C}\right)$} & \multicolumn{4}{|c|}{ Rainfall (mm) } \\
\hline & 1991-2010 & 2016 & 2017 & 2018 & 1991-2010 & 2016 & 2017 & 2018 \\
\hline January & 0.1 & 0.3 & -4.3 & 3.2 & 23.9 & 48.2 & 28.6 & 43.5 \\
\hline February & 1.6 & 5.0 & 2.7 & -2.0 & 21.3 & 50.9 & 31.7 & 37.4 \\
\hline March & 5.4 & 5.3 & 8.3 & 2.6 & 40.4 & 41.5 & 26.4 & 29.0 \\
\hline April & 10.1 & 10.3 & 8.9 & 15.5 & 43.1 & 64.2 & 73.1 & 15.9 \\
\hline May & 15.0 & 14.3 & 15.7 & 17.8 & 66.1 & 120.9 & 78.2 & 86.0 \\
\hline June & 18.1 & 18.8 & 21.0 & 19.2 & 86.8 & 104.7 & 41.7 & 118.2 \\
\hline July & 19.8 & 20.7 & 20.6 & 21.0 & 89.4 & 118.6 & 140.7 & 114.0 \\
\hline August & 19.3 & 19.2 & 21.4 & 22.6 & 75.0 & 47.1 & 59.8 & 112.2 \\
\hline September & 14.7 & 17.9 & 13.8 & 16.9 & 71.4 & 63.3 & 106.2 & 70.0 \\
\hline October & 9.9 & 8.8 & 11.1 & 12.6 & 37.0 & 113.4 & 60 & 16.5 \\
\hline November & 5.0 & 4.3 & 4.7 & 5.7 & 37.6 & 57.9 & 38.6 & 58.4 \\
\hline December & 0.4 & 0.7 & 1.7 & 2.4 & 36.9 & 20.6 & 24.8 & 86.1 \\
\hline Jan-Dec & 9.9 & 10.5 & 10.5 & 11.5 & 628.9 & 851.3 & 709.8 & 787.2 \\
\hline
\end{tabular}

treatment in spring in both experiments. Herrera and Liedgens (2009) reported that reductions in N leaching due to non-winter hardy catch crops were achieved mainly by avoiding the fallow period during autumn and winter. Accordingly, winter-hardy $\mathrm{CC}$ that continue growth during winter can be expected to have a more pronounced effect on diminishing $\mathrm{N}$ leaching losses than freeze-killed CCs that terminate growth during winter. According to this, in a study by Rüegg et al. (1998), winter-hardy rye achieved lower $\mathrm{N}_{\text {in }}$ values in spring compared with a freeze-killed mixture consisting of phacelia and white mustard. Nitrogen mineralization from the residues of the freeze-killed CC mixture may already increase $\mathrm{N}_{\text {in }}$ contents during winter. In contrast, the winter-hardy CC mixture in our study took up soil nitrogen until termination in April, thus reducing $\mathrm{N}_{\text {in }}$ contents after winter and the risk of nitrate leaching during winter, saving nitrogen for the following main crop.

Otherwise, sowing maize without inverting soil cultivation was more difficult in the winter-hardy $\mathrm{CC}$ treatment than in the treatment where the $\mathrm{CC}$ mixture was freeze-killed. But mainly due to the effective CC termination with the rotary cultivator, weed density was not
Fig. 1 Soil inorganic $\mathrm{N}\left(\mathrm{kg} \mathrm{ha}^{-1}\right)$ in $0-0.9 \mathrm{~m}$ of cover crops mixtures in spring and summer 2017 and 2018. WCC, winterhardy cover crop; FCC, freezekilled cover crop. Mean values with same letter at the same date do not differ significantly $(P<$ 0.05 )

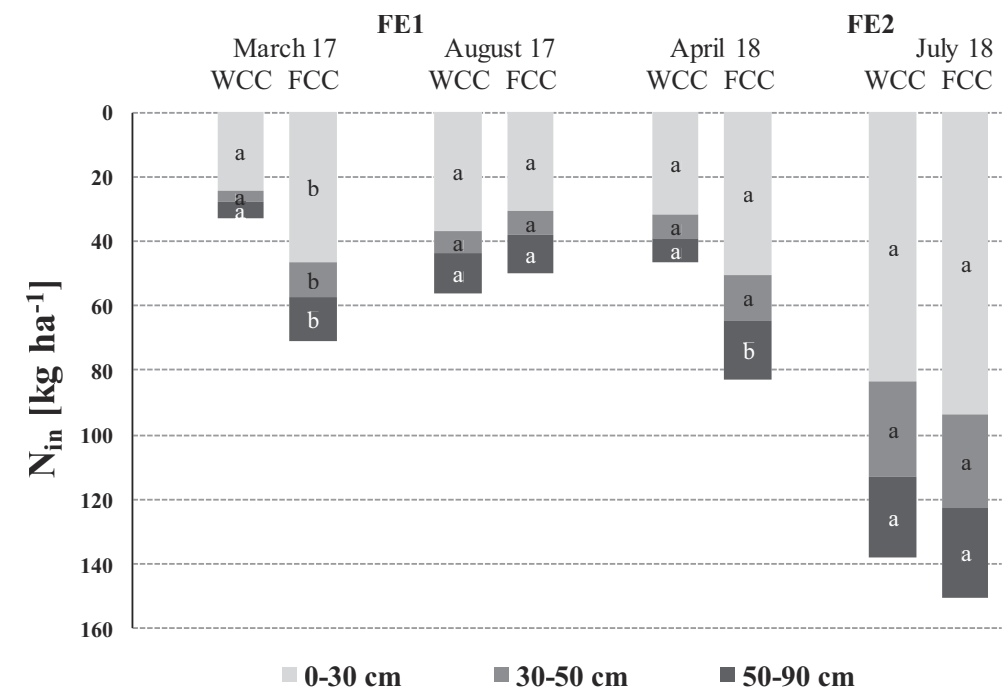


Table 2 Cover crop above-ground dry matter (CC DM), maize grain dry matter yield (maize DM) and maize $\mathrm{N}$ yield (maize $\mathrm{N}$ yield) in both field experiments; Significance of treatment effects $(\operatorname{Trtm})$, year and Trtm $\times$ year

\begin{tabular}{|c|c|c|c|c|c|c|c|c|c|}
\hline \multirow{2}{*}{$\begin{array}{l}\text { Treatment } \\
\text { Winter-Hardy CC }\end{array}$} & \multirow{2}{*}{$\begin{array}{l}\text { Experiment } \\
\text { FE1 }\end{array}$} & \multicolumn{2}{|c|}{$\begin{array}{l}\text { CC DM Nov. mean } \pm \mathrm{SD} \\
\left(\mathrm{t} \mathrm{ha}^{-1}\right)\end{array}$} & \multicolumn{2}{|c|}{$\begin{array}{l}\text { CC DM Apr. mean } \pm \\
\text { SD }\left(\mathrm{t} \mathrm{ha}^{-1}\right)\end{array}$} & \multicolumn{2}{|c|}{$\begin{array}{l}\text { Maize DM mean } \pm \text { SD } \\
\left(\mathrm{t} \mathrm{ha}^{-1}\right)\end{array}$} & \multicolumn{2}{|c|}{$\begin{array}{l}\text { Maize } \mathrm{N} \text { yield mean } \pm \mathrm{SD} \\
\left(\mathrm{kg} \mathrm{ha}^{-1}\right)\end{array}$} \\
\hline & & $1.90 \mathrm{a}$ & 0.38 & 3.24 & 0.93 & $7.29 \mathrm{a}$ & 1.26 & $91.9 \mathrm{a}$ & 13.8 \\
\hline & FE2 & $1.73 \alpha$ & 0.35 & 2.34 & 0.44 & $7.32 \alpha$ & 1.94 & $100.4 \alpha$ & 26.5 \\
\hline & Av. & $1.82 \mathrm{~A}$ & 0.15 & 2.79 & 0.55 & $7.31 \mathrm{~A}$ & 1.57 & $96.1 \mathrm{~A}$ & 18.9 \\
\hline \multirow[t]{3}{*}{ Freeze-killed CC } & FE1 & $3.27 \mathrm{~b}$ & 0.56 & - & & $8.33 \mathrm{a}$ & 1.63 & $101.9 \mathrm{a}$ & 20.4 \\
\hline & FE2 & $2.92 \beta$ & 0.81 & - & & $6.58 \alpha$ & 2.99 & $92.4 \alpha$ & 49.4 \\
\hline & Av. & $3.10 \mathrm{~B}$ & 0.46 & - & & $7.46 \mathrm{~A}$ & 1.52 & $97.2 \mathrm{~A}$ & 21.8 \\
\hline Trtm & & 0.001 & & - & & 0.887 & & 0.951 & \\
\hline Year & & 0.368 & & 0.129 & & 0.420 & & 0.975 & \\
\hline Trtm $\times$ year & & 0.753 & & - & & 0.405 & & 0.566 & \\
\hline
\end{tabular}

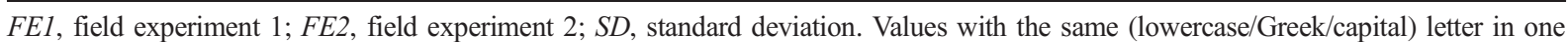
column are not significantly different $(P<0.05)$.

higher in these treatments except for one assessment date in July 2018 in FE2 and did not affect maize grain yield significantly. Similar to our results, Rüegg et al. (1998) found no differences in the number of maize plants per square meter between a freeze-killed CC mixture and a winter-hardy rye CC. Reimer et al. (2019) tested the effect of CC on weed pressure in a non-inversion tillage system at six sites throughout northern and central Europe. The CCs could contribute to weed control but could not fully compensate for reduced weed control of non-inversion tillage. The authors recommended using non-inversion tillage together with CCs primarily in low weed pressure environments. The experimental site of our study can, due to its climatic conditions with rather low average annual precipitation $(629 \mathrm{~mm})$, be regarded as being a low weed pressure environment. But still, mainly thistle density was high on the experimental plots, presumably due to the non-inversion tillage history of the farm.

Maize grain DM yield was lower in FE2 than in FE1 in the freeze-killed CC treatment. This corresponds to less precipitation and hot weather in spring 2018 in FE2. Rüegg et al. (1998) found lower silage maize dry matter yields after a winter-hardy rye CC compared with a freeze-killed CC mixture consisting of phacelia and white mustard, both cultivated under minimum tillage. On the contrary, silage maize DM yield did not differ significantly after a winter-hardy CC mixture (Landsberger Gemenge, $12.9 \mathrm{t} \mathrm{ha}^{-1}$ ) compared with a freeze-killed CC mixture of legumes and non-legumes (12.0 t ha $\left.{ }^{-1}\right)$
Fig. 2 Weed pressure (\%) over time for both treatments in 2018 . WCC, winter-hardy cover crop; FCC, freeze-killed cover crop

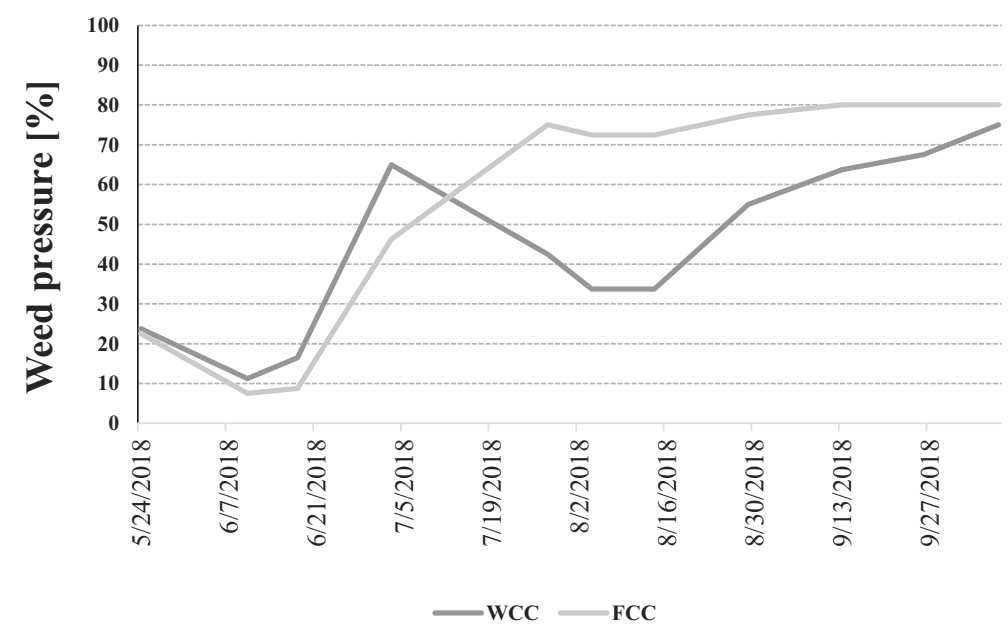

WCC: winter-hardy cover crop; FCC: Freeze-killed cover crop. 
in the 3-year study of Schließer et al. (2010). Kramberger et al. (2014) found lower maize yields following pure Italian ryegrass stands or non-legume-dominated mixtures compared with $\mathrm{CC}$ mixtures with a high legume content. Kolbe (2007) found that both non-legume CCs and $\mathrm{CC}$ mixtures consisting of legumes and non-legumes lead to decreased maize grain DM yields compared with pure legume CC mixtures, irrespective of the coldhardiness of the CCs. He concluded that CCs with a high C-to-N ratio should be avoided because they lead to subsequent $\mathrm{N}$ immobilization in the soil and negative yield effects in the following crop. Obviously, the legume content of $\mathrm{CC}$ mixtures, implying a low $\mathrm{C}$-to- $\mathrm{N}$ ratio in the $\mathrm{CC}$ biomass, is more relevant for the $\mathrm{N}$ availability and consequent maize grain yield than the cold hardiness of the $\mathrm{CC}$ mixture.

In our study, both freeze-killed and winter-hardy CC mixtures consisted of a legume-dominated legume-nonlegume mixture. This resulted in a narrow C-to-N ratio (10 to 13 ) in the $\mathrm{CC}$ biomass as a basis for a swift $\mathrm{N}$ mineralization from the $\mathrm{CC}$ residues in both treatments. Accordingly, maize grain DM yield and maize grain $\mathrm{N}$ yield did not differ between the $\mathrm{CC}$ treatments in our study. Obviously, other growth factors, mainly water availability and weed competition, were more relevant for the maize crop yield than $\mathrm{N}$ availability in our experiment.

\section{Conclusion}

A winter-hardy $\mathrm{CC}$ mixture reduced inorganic $\mathrm{N}$ contents in 0-90-cm soil depth after winter by approximately $50 \%$ compared with a freeze-killed CC mixture. In this way, the risk of nitrate leaching is significantly reduced. More $\mathrm{N}$ is preserved in plant biomass and can be transferred to a following maize crop.

An enhanced risk of weed competition by re-growing $\mathrm{CC}$ plants was expected in the winter-hardy CC mixture compared with the freeze-killed CC mixture. Therefore, a rotary cultivator with a higher soil cultivation intensity was used for terminating the winter-hardy CCs, while soil cultivation in the freeze-killed CC treatment was done by chiselling. By this adaption of soil cultivation to the $\mathrm{CC}$ mixture, the resulting weed density, dominated by creeping thistle occurring in patches on the plots, was similar in both treatments.

The CC treatment did not affect grain yield and $\mathrm{N}$ yield of a following grain maize crop. Obviously, weather conditions and weed competition were more relevant for maize yield.

Combined with an adapted soil cultivation, both the winter-hardy and freeze-killed cover crop mixture were suitable options before grain maize in an organic farming system with non-inversion tillage under moderately dry site conditions. The winter-hardy CC mixture can be regarded as advantageous over the freeze-killed CC mixture because it reduced the risk of nitrate leaching without impairing growth and yield of a following grain maize crop.

Acknowledgements The authors are grateful to B. Blankenhorn, D. Fritzsche, J. Kurzbauer, A. Oswald, A. Surböck, M.-L. Wohlmuth and S. Zeidler for their support during the field experiment, laboratory analyses, statistical calculations, discussion of the results and formatting the text.

Funding information Open access funding provided by University of Natural Resources and Life Sciences Vienna (BOKU). This study was funded by the Austrian Federal Ministry for Agriculture, Regions and Tourism, and by the European Fund for Development of Rural Areas.

Open Access This article is licensed under a Creative Commons Attribution 4.0 International License, which permits use, sharing, adaptation, distribution and reproduction in any medium or format, as long as you give appropriate credit to the original author(s) and the source, provide a link to the Creative Commons licence, and indicate if changes were made. The images or other third party material in this article are included in the article's Creative Commons licence, unless indicated otherwise in a credit line to the material. If material is not included in the article's Creative Commons licence and your intended use is not permitted by statutory regulation or exceeds the permitted use, you will need to obtain permission directly from the copyright holder. To view a copy of this licence, visit http://creativecommons.org/licenses/by/4.0/.

\section{References}

Bodner G, Himmelbauer M, Loiskandl W, Kaul HP (2010) Improved evaluation of cover crop species by growth and root factors. Agron Sustain Dev 30:455-464

Herrera JM, Liedgens M (2009) Leaching and utilization of nitrogen during a spring wheat catch crop succession. J Environ Qual 38:1410-1419

Kolbe H (2007) Zwischenfrüchte als Vorfrüchte für die Ertragsund Qualitätsleistung von Mais und Kartoffeln. In: Zikeli S, Claupein W, Dabbert S, Kaufmann B, Müller T, Valle Zárate A (eds) Beiträge zur 9. Wissenschaftstagung Ökologischer Landbau, band 1. Dr. Köster, Berlin, pp 145-148

Kramberger B, Gselman A, Kristl J, Lesnik M, Sustar V, Mursec M, Podvrsnik M (2014) Winter cover crop: the effects of grass-clover mixture proportion and biomass management on maize and the apparent residual $\mathrm{N}$ in the soil. Eur J Agron 55:63-71 
Reimer M, Ringselle B, Bergkvist G, Westaway S, Wittwer R, Baresel JP, Van Der Heijden MGA, Mangerud K, Finckh MR, Brandsæter LO (2019) Interactive effects of subsidiary crops and weed pressure in the transition period to noninversion tillage, a case study of six sites across northern and Central Europe. Agronomy 9:495. https://doi. org/10.3390/agronomy9090495

Rinnofner T, Friedel JK, de Kruijff R, Pietsch G, Freyer B (2008) Effect of catch crops on $\mathrm{N}$ dynamics and following crops in organic farming. Agron Sustain Dev 28:551-558

Rüegg WT, Richtner W, Stamp P, Feil B (1998) Accumulation of dry matter and nitrogen by minimum-tillage silage maize planted into winter cover crop residues. Eur J Agron 8:59-69

Schlichting E, Blume HP, Stahr K (1995) Bodenkundliches Praktikum - Eine Einführung in pedologisches Arbeiten für Ökologen, insbesondere land- und Forstwirte und für
Geowissenschaftler, 2. neubearbeitete Auflage. Blackwell Wissenschafts-Verlag, Berlin, Wien

Schließer I, Schuster M, Kolbe H (2010) Einfluss verschiedener Zwischenfrüchte als Vorfrüchte für die Ertrags- und Qualitätsleistung von Silomais und Kartoffeln. Schriftenreihe des Landesamtes für Umwelt, Landwirtschaft und Geologie 27/2010. https://doi.org/10.4126/98004000823

Wanic M, Żuk-Gołaszewska K, Wanic M, Orzech K (2018) Catch crops and the soil environment $-\mathrm{a}$ review of the literature. $\mathrm{J}$ Elem 24:31-45

Publisher's note Springer Nature remains neutral with regard to jurisdictional claims in published maps and institutional affiliations. 